\title{
Zapredkarice (Cephalcia spp.) na vejah navadne smreke na Koroškem pri Prevaljah
}

\author{
Maja JURC $^{1 *}$, Gorazd MLINŠEK ${ }^{2}$
}

V Sloveniji so prvi obsežen ter močan napad zapredkaric iz rodu Cephalcia (Hymenoptera-kožekrilci: Symphyta-rastlinske ose, Pamphiliidae-zapredkarice ali prelke) opazili gozdarji dne 2. 7. 2009 v OE Slovenj Gradec, GGE Ravne. Namnožitev zapredkaric se je pojavila na pobočjih nad zahodnim delom Prevalj na Riflovem vrhu na površini 48 ha ter na nadmorski višini med 600-800 m. Gozd s povprečno lesno zalogo čez $300 \mathrm{~m}^{3}$ na hektar je dobro gospodarjen in ohranjen, $\mathrm{v}$ njem prevladuje smreka (več kot $70 \%$ ), bukev, macesen in rdeči bor. Zapredkarice so na vejah od 60 do 90 let starih, predvsem vitalnih smrek, oblikovale velike, rahle zapredke iz svojih iztrebkov v katerih poteka razvoj ličink (pagosenic) (slika 1). Na vzorčni veji dolgi $124 \mathrm{~cm}$ smo v zapredkih ugotovili 172 ličink (odrezana je bila na posekani smreki dne 10. 7. 2009). Ličinke so se razlikovale po velikosti, barvi ter vrstnih značilnostih. Poškodbe je povzročilo več avtohtonih evroazijskih vrst rastlinskih os, zapredkaric iz rodu Cephalcia.

Cephalcia spp. so holarktične vrste, za katere je znano, da povzročajo obsežne defoliacije iglavcev iz družine Pinaceae, posebej smrek (Picea spp.), borov (Pinus spp.), macesnov (Larix spp.), občasno ceder (Cedrus spp.), zelo redko jelk (Abies spp.). Po novejših virih je v Evropi znanih več kot 10 vrst, ki se pojavljajo na smrekah in na macesnih, v Italiji so jih ugotovili tudi na jelkah.

Biologija vseh vrst je podobna, vendar se razlike pojavljajo tudi v okviru vrste. Samice niso zelo mobilne, prilezejo iz tal kjer so prezimile, rojijo od aprila do julija, včasih tudi avgusta (odvisno od vrste), po kopulaciji na tleh in na pritalni vegetaciji odložijo večje število jajčec na iglice vej v spodnjem delu krošnje gostiteljskih dreves. Zaradi tega postanejo lažje in lahko nato letijo višje v krošnje ter tam odložijo preostala jajčeca (do 120). Samci so bolj mobilni in letijo. Imagi so v povprečju od 8 do $14 \mathrm{~mm}$ dolge osice, pri mirovanju imajo krila zložena čez zadek, hranijo se predvsem z mano. Ličinke so dolge od 15-22 mm, razvijajo v rahlih zapredkih v svilnatih tulcih na vejah, ki jih sproti gradijo, levijo se večkrat, kar je odvisno od vrste in spola razvijajoče se osice (slika 2). Razvoj ličink evropskih vrst traja od 30 do 45 dni. Ličinke se v zadnji razvojni fazi spustijo na tla in se zarijejo v prst od 5 do $15 \mathrm{~cm}$ globoko, kjer oblikujejo ovalne kamrice iz prsti. V tleh se preobrazijo $\mathrm{v}$ predbube (eo- in pronimfe), pozneje v bube in zaključijo razvoj v enem, dveh ali več letih. Vrste rodu Cephalcia, ki živijo na smrekah se med sabo ločijo po času izvalitve odraslih osebkov, reprodukcijskem potencialu, starosti iglic, ki jih samice uporabljajo za ovipozicijo in obnašanju ličink.
V naših vzorcih je prevladovala vrsta Cephalcia arvensis Panzer 1805. Prav C. arvensis je ena od najpogostejših vrst, ki povzroča defoliacije v srednji Evropi in je morfološko, biološko in genetsko zelo variabilna. Pogosto se v gradaciji pojavi več vrst skupaj, zato menimo, da je glede na morfološko variabilnost najdenih ličink, tudi na lokaciji pri Prevaljah, prisotnih več različnih vrst (sliki 3 in 4).

Kalamitete različnih vrst zapredkaric so pogoste v centralni Evropi, občasno se so pojavljale tudi v severnih območjih (severna Italija, Danska, Češka republika, Slovaška, Nemčija, Luksemburg, Poljska). V namnožitev prehajajo predvsem vrste C. abietis, C. alpina, $C$. arvensis ter $C$. annulicornis. Vzroki za te pojave so različni: oslabljeno ali zaradi drugih biotskih ali abiotskih dejavnikov prizadeto drevje (npr. močan vodni stres gostiteljskih dreves), ustrezne ekološke razmere za razvoj zapredkaric (manjša mortaliteta žuželk zaradi višjih temperatur in manj padavin $\mathrm{v}$ času pred namnožitvijo, sušno in vroče vreme $\mathrm{v}$ času prehranjevanja larv), spremenjena kvaliteta hranil v iglicah kot rezultat vodnega stresa gostiteljskih rastlin v preteklosti, nezadostna količina naravnih patogenov ali naravnih sovražnikov zapredkaric v sestojih. Gradacija C. arvensis v severni Italiji v obdobju 1985-1992 je bila pogojena $\mathrm{z}$ dvigom temperatur tal nad pragom $12^{\circ} \mathrm{C}$, ki je povzročil prekinitev diapavze in hitrejši razvoj pronimf in bub v tleh. Veliki namnožitvi zapredkarice pa ni sledila namnožitev naravnih sovražnikov, kar je privedlo do večletne kalamitete. Defoliacije vrst rodu Cephalcija zmanjšujejo priraščanje gostiteljskih dreves, jih slabijo in naredijo občutljive za poškodbe drugih biotskih ali abiotskih dejavnikov.

$\mathrm{V}$ talnih vzorcih, ki smo jih nabrali na Riflovem vrhu dne 17. 7. 2009, smo na $\mathrm{m}^{2}$ tal ugotovili 1770 eonimf in / ali pronimf, kar pomeni, da lahko z veliko zanesljivostjo pričakujemo gradacijo zapredkaric tudi v naslednjem (naslednjih) letih (škodljive defoliacije se začenjajo pri 20 pronimf $\mathrm{v}$ spomladanskem času $/ \mathrm{m}^{2}$ tal ali 14.26 adultov/rumeno lepljivo past) (slika 5).

\section{Viri}

Battisti A., Boato A., Cescatti A., Ros Da N., Massuttii L., Stergulc F., Zanocco D. 1994. Cephalcia arvensis, Nelle Peccete prealpine del Veneto. Università degli Studi di Padova, Arti Grafiche Padovane: 111 str.

Battisti A. 1993. Bionomics of the spruce web-spinning sawfly Cephalcia arvensis Pancer (Hym., Pamphiliidae) in Northeastern Italy. J. Appl. Ent, 115: 52-61

Jurc M. 2009. Predhodno poročilo o pojavu zapredkaric (Pamphiliidae:Cephalcia) na vejah navadne smreke na Koroškem. Ljubljana: Poročevalska, diagnostična in prognostična služba za varstvo gozdov, Gozdarski inštitut Slovenije, Oddelek za gozdarstvo in obnovljive gozdne vire BF: 5 str. 
Pschorn-Walcher H. 1982. Symphyta, Planzenwespen. V: Die Forstschädlinge Europas. Bd. 4. Schwenke W. (ur.). Hamburg u. Berlin, Verlag Paul Parey: 188-191

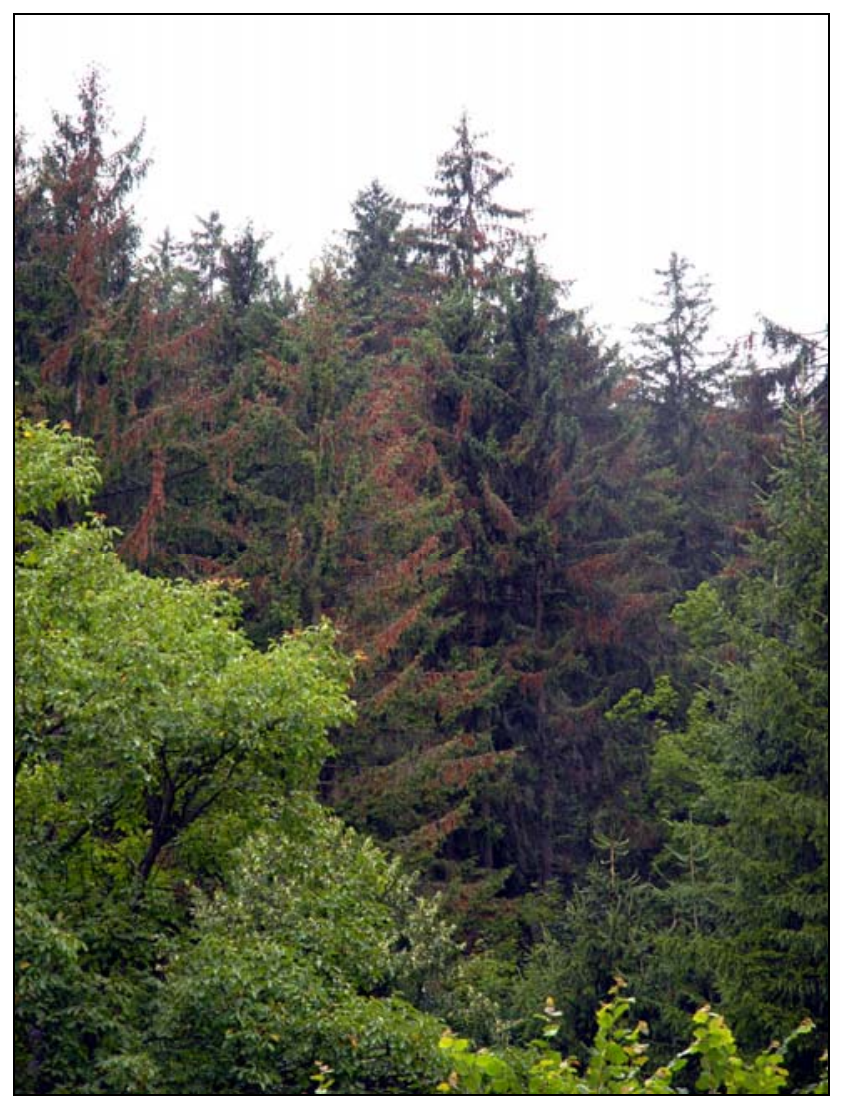

Slika 1: Napadene smreke na pobočjih nad zahodnim delom Prevalj na Riflovem vrhu, slikano 10.7.2009

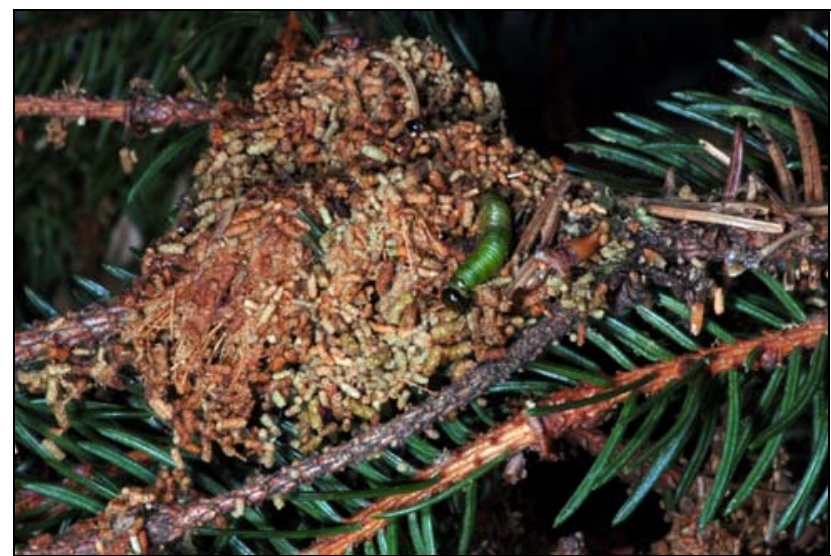

Slika 2: Zapredek s pagosenico Cephalcia sp.
1Univerza v Ljubljani, Biotehniška fakulteta, Oddelek za gozdarstvo in obnovljive gozdne vire Večna pot 83, 1000 Ljubljana; 2Zavod za gozdove Slovenije, Območna enota Slovenj Gradec, Vorančev trg 1, 2380 Slovenj Gradec *maja.jurc@bf.uni-lj-si

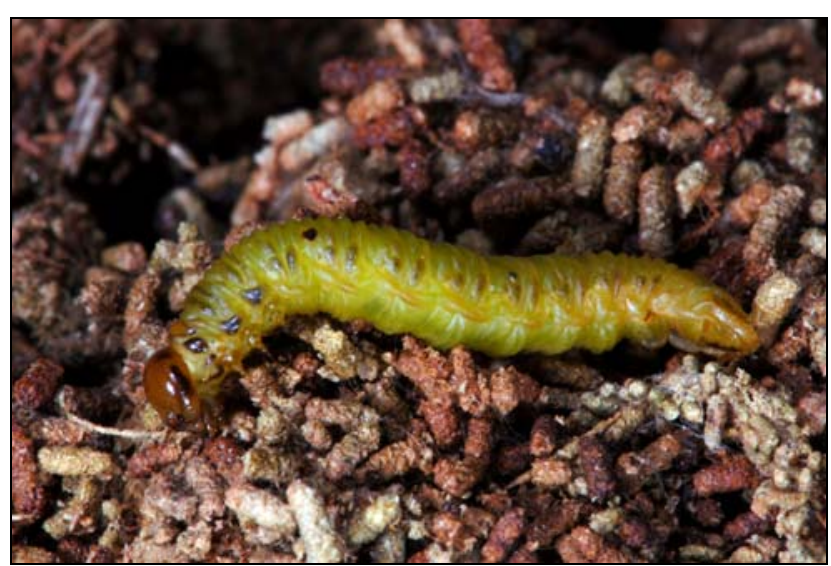

Slika 3: Pagosenica ima tri pare oprsnih nog ter par potiskalk na zadkovih segmentih 


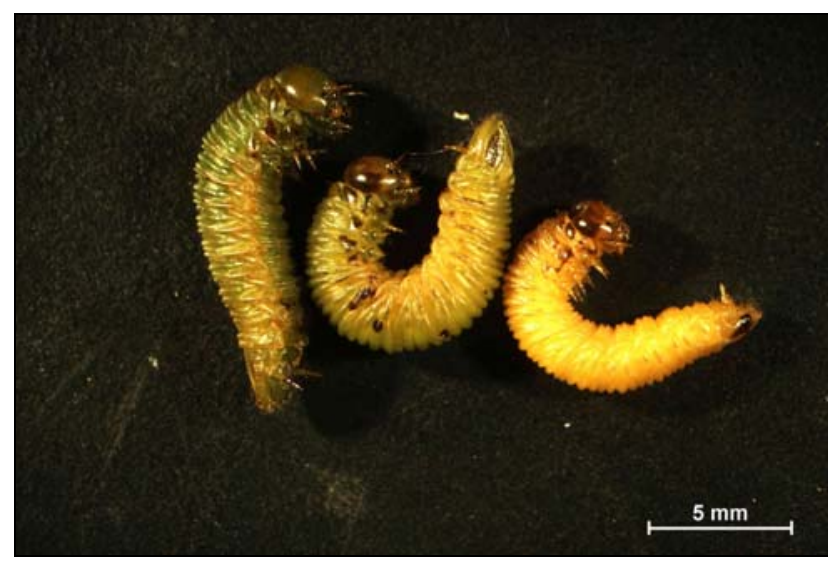

Slika 4: Morfološka variabilnost nabranih ličink (vzorec je bil nabran 10.7.2009)

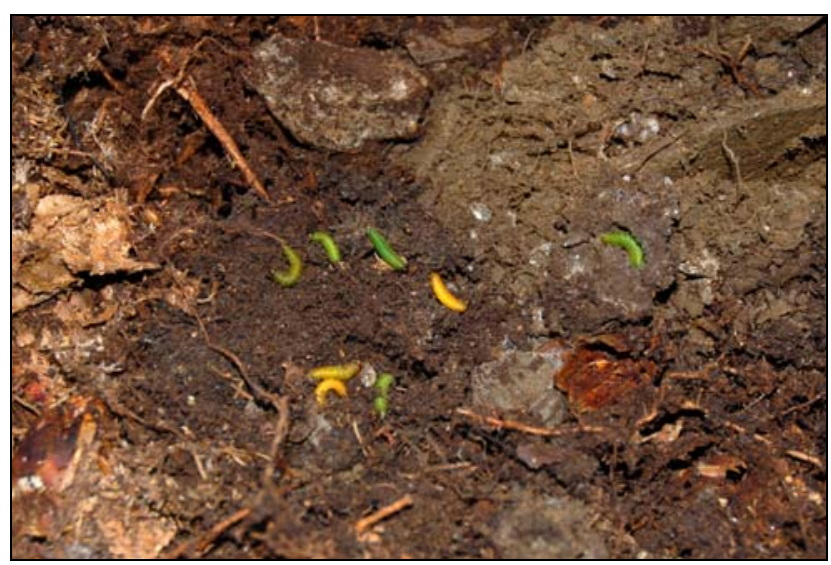

Slika 5: Iz števila osebkov pronimf, ki prezimijo v tleh, lahko sklepamo o velikosti populacij vrst rodu Cephalcia ter napovemo defoliacijo (slikano 18.8.2009)

\section{Osip smrekovih iglic, Lirula macrospora}

\section{Tine HAUPTMAN ${ }^{1 *}$, Marijan DENŠA ${ }^{2}$}

Osip smrekovih iglic, ki ga povzroča gliva Lirula macrospora (R. Hartig) Darker, je v letošnjem letu prizadel območje OE Nazarje, simptome bolezni pa smo opazili tudi v drugih delih Slovenije. Gliva spomladi okužuje letošnje, lahko pa tudi lanskoletne iglice, ki po okužbi sprva porumenijo in kasneje porjavijo (slika 1). $\mathrm{Na}$ odmrlih iglicah se najprej razvijejo piknidiji anamorfa Hypodermina hartigii Hilitzer, ki so $\mathrm{v}$ obliki mehurčkov (slika 2). Piknidiji vsebujejo veliko število 2,5-3,5 × 1,5-2,5 $\mu \mathrm{m}$ velikih konidijev, ki pa za širjenje bolezni nimajo pomena (imajo funkcijo spermacijev). Kasneje, odvisno od vremenskih razmer, se na iglicah razvijejo podolgovata, več $\mathrm{mm}$ dolga spolna trosišča - histeroteciji (slika 3), ki so najprej rjave kasneje pa črne barve. V njih nastajajo aski (slika 4) z nitastimi askosporami, ki spomladi ponovno povzročajo nove okužbe. Značilni simptom okužbe z glivo Lirula macrospora so tudi črne linije $\mathrm{v}$ obliki obročka na osnovi okuženih iglic (slika 3). Na tem mestu se kopičijo fenolne substance, ki zaustavljajo proces odpadanja odmrlih iglic. Zato odmrle iglice še dolgo ostanejo pritrjene na veji (Maček, 2008; Butin, 1995).
Gliva povzroča močnejše okužbe in s tem prezgodnje odmiranje iglic predvsem na vlažnih legah, bolj pa so občutljive iglice, ki so premalo osvetljene. Tako najpogosteje prizadene podrasla drevesa, lahko pa tudi spodnje, zesenčene veje višjih dreves. Kljub vsemu bolezen ni gospodarsko pomembna in zato zatiranje navadno ni potrebno (Maček, 2008). Priporočamo redčenje mladja, saj se tako zmanjša vlažnost mikrorastišča in s tem verjetnost okužbe. Iglice tako dobijo več svetlobe in so zato odpornejše.

\section{Viri}

Butin H. 1995. Tree diseases and disorders. Causes, Biology and Control in Forest and Amenity Trees. Oxford, USA, Oxford Univ. Press: 261 str.

Maček J. 2008. Gozdna fitopatologija. Ljubljana, Zavod za gozdove Slovenije, Zveza gozdarskih društev Slovenije, Gozdarska založba: 448 str.

${ }^{1}$ Gozdarski inštitut Slovenije, Večna pot 2, 1000 Ljubljana; ${ }^{2 Z a v o d ~ z a ~ g o z d o-~}$ ve Slovenije, Območna enota Nazarje, Savinjska cesta 4, 3331 Nazarje *tine.hauptman@gozdis.si 